\title{
Sales, D. (2017). José María Arguedas y el cine. Madrid: Iberoamericana-Vervuert.
}

Debido a que la bibliografía sobre la obra de José María Arguedas es, por decir lo menos, extensa hasta la intimidación, un primer mérito de la autora de este libro, la investigadora, escritora y traductora española Dora Sales, es haber elegido un tema de estudio prácticamente ausente de esta profusión, aunque bastante relevante para diversos grupos de lectores: el acercamiento que tuvo Arguedas al cine, así como la influencia de su obra en la producción fílmica nacional.

La relación del escritor con este campo ha sido abordada antes de manera fugaz, en artículos académicos y notas breves desperdigados en revistas, periódicos, blogs y sobre puntos específicos, no con la visión panorámica que ofrece esta publicación, articulada alrededor de tres ejes. En el primero se relatan las diferentes formas en las que el autor se relacionó en vida con lo audiovisual: su labor de apoyo a la Escuela de Cine del Cusco (fundada en 1955 por Eulogio Nishiyama, Luis Figueroa, Manuel Chambi [hijo del reconocido fotógrafo] y Rodolfo Zamolloa), sus preferencias como cinéfilo y su propio manejo de la cámara fotográfica. En el segundo, se presenta un recuento crítico de películas, producidas dentro y fuera del Perú, basadas en la literatura arguediana. La última parte está dedicada a las reflexiones de dos realizadores peruanos contemporáneos, Javier Corcuera y Claudia Llosa, quienes han declarado una influencia de la obra y pensamiento de Arguedas en sus cinematografías.

El primer capítulo se compone principalmente de la reproducción y análisis de material de archivo (artículos periodísticos, cartas, afiches de películas, fotogramas y fotografías), en una parte inédito y en otra republicado de fuentes diversas, $y$, como complemento, incluye una entrevista de Sales a la cineasta Gabriela Martínez, cercana al colectivo cusqueño de cineastas. Lo que podemos concluir de este apartado es que, si bien Arguedas escribió una sola crítica de cine - "Películas de gesta" (1957)-, su interés por impulsar una tradición filmográfica nacional, en ciernes en ese momento, no era modesto. Algo de ello se refleja en el mencionado artículo, publicado por primera vez en El Comercio y que se reproduce en este libro. En él Arguedas afirma con entusiasmo: "Ni la música ni la literatura tienen, lo sabemos bien, el poder y expresión de la plástica. En la película se puede dar la confluencia de la música y de la plástica; de la plástica viva, dinámica y múltiple: danza, gestos, mímica, caminata y carrera, y no solo la del ser humano sino la de las bestias que ha domesticado. [EI cine] Es el arte que recogería lo que no alcanzamos a describir bien, en el Perú, los literatos mestizos" (p. 25).

Sin embargo, su activismo cinematográfico se ha-
Ila principalmente fuera de las publicaciones, como se deduce de la documentación incluida en este capítulo. Durante la década de 1950, Arguedas difunde en Lima el trabajo del colectivo de realizadores cusqueños, los asesora y discute con ellos en un intercambio epistolar la necesidad de modificar algunas representaciones estereotipadas del mundo andino que habían filmado en Kukuli (1961), nada menos que el primer largometraje peruano de ficción hablado en quechua. También impulsa un proyecto etnográfico de registro en audio y video de danzas andinas en diferentes ciudades como Puno, Cajamarca, Cusco, Huancavelica, Huancayo, cuyo material es hoy custodiado por la Escuela Nacional Superior de Folklore José María Arguedas. Es interesante también la selección sobre la incursión fotográfica del escritor durante su estadía en la comunidad española de Sayago en 1958, y en Chimbote, en 1969, mientras escribía El zorro de arriba y el zorro de abajo. Esta no solo se basa en el material publicado en los tomos de la editorial Horizonte y del Instituto de Estudios Peruanos (Obra antropológica, 7 tomos, 2013), sino también en hallazgos más recientes.

Un tema completamente inédito es la exploración germinal del lado cinéfilo de Arguedas. A partir de los testimonios familiares y de la correspondencia con los cineastas cusqueños, Sales determina algunas películas que con certeza impactaron al escritor: Los siete samuráis, de Akira Kurosawa (1954); Orfeo Negro (1959), de Marcel Camus; y Un hombre y una mujer (1966), de Claude Lelouch. Apoyada en estas preferencias y en algunas ideas de Martin Lienhard sobre la hipotética influencia del cine soviético de los años veinte en El zorro de arriba y el zorro de abajo, la investigadora desliza "la posibilidad de que Arguedas no solo bebiese de la vida misma y de lecturas literarias, antropológicas y de otros ámbitos, sino también de narrativas cinematográficas" (p. 72), y en el caso puntual de su novela póstuma, de las perspectivas múltiples de otro emblemático filme de Kurosawa, Rashomon (p. 70).

Los capítulos 2 y 3 contienen la parte más fresca del libro, pues se enfocan en cómo distintos realizadores han tomado de base la narrativa arguediana, y en menor medida la vida del autor para elaborar sus filmes, así como en aquellos proyectos que, en la etapa de investigación del libro, aún no habían sido estrenados o concluidos: el western "Pueblo viejo" (2015), de Hans Matos Cámac, y la película animada "Nuna, la agonía del wamani", de Jimy Carhuas Tintaya.

A partir de la exhaustiva contextualización que se realiza sobre cada propuesta, corroboramos una constante en la cinematografía nacional: la falta de recursos, 
sobre todo económicos, para llevar a buen puerto esta clase de proyectos. Pero, más allá de la factura técnica, la autora advierte una realidad paradójica a nivel ideológico: coincide con los críticos de cine Mónica Delgado y Rodrigo Portales al considerar que la mayoría de adaptaciones no se corresponden con la visión arguediana del mundo andino, a excepción del cortometraje "Danzak" (2008), una versión modernizada, feminista, del cuento "La agonía de Rasu-Ñiti", dirigido por la peruana Gabriela Yépez. El libro cierra con las entrevistas a esta realizadora, así como a Claudia Llosa y Javier Corcuera, lectura que nos da muchas luces sobre cómo la obra arguediana funge de puente para acercar a los cineastas urbanos y cosmopolitas al mundo andino.
José María Arguedas y el cine resulta así un aporte pionero $y$, por ello, exploratorio que proporciona e inspira novedosas entradas al estudio multi- o transdisciplinario del legado de Arguedas, de su presencia en la cinematografía y en otros espacios artísticos. A título personal, queda mucho por explorar en su relación con lo audiovisual, no solo por los datos que generosamente se consignan en el libro sobre el posible material de archivo por rastrear, sino porque se pueden entablar otros puntos de diálogo o discusión entre la propuesta arguediana y las cinematografías emergentes de los últimos años: el cine regional e indígena, y a escala latinoamericana, el llamado documental especulativo.

\section{Luz Vargas de la Vega}

Contacto: vargas.la@pucp.pe

Pontificia Universidad Católica del Perú, Lima, Perú

https://orcid.org/0000-0002-0896-7588 